\title{
Macro plus micro approach to English academic writing
}

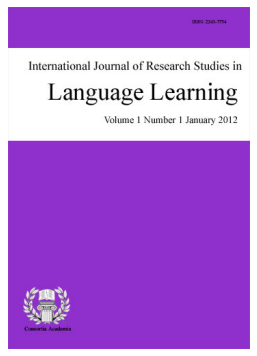

Li, Xiao Wen $\gtrsim$

School of Foreign Languages, Harbin Institute of Technology, China (xiaowenli@hit.edu.cn)

\section{Abstract}

Based on the relevant literature review and the author's years of teaching experiences, this paper presents a new teaching method for English academic writing, called macro plus micro approach to English academic writing, which is put forward and practiced under the circumstances of the urgent needs of doctoral students for publications in international refereed journals, or for delivering their presentations at conferences. The specific pedagogical measures taken in this course are introduced, including the critical activities conducted, as well as the assessment from both the perspectives of the teacher and the students, confirming the ideas that an effective teaching method of English For Specific Purpose (ESP) should be established based more on the practical analyses of the needs of students' outcome goals and subsequent activities undertaken in class, than on theoretical text books alone, so as to solve the bottlenecks that hold back the successful publications of $\mathrm{PhD}$ students' research papers written in English.

Keywords: macro plus micro approach; English academic writing; needs analysis; outcome goals 


\section{Macro plus micro approach to English academic writing}

\section{Introduction}

Macro plus micro approach to English academic writing refers to the kind of teaching and learning process that characterizes an integration of teaching and learning English in academic writing established based on the perspectives of the teacher and students, including teaching and learning materials that are originated from the teacher and students and an interaction between students and teachers or peers in and after class. Macro approach means that the teaching and learning method is planned targeting at the whole class while micro approach means that specific measures are taken to meet each individual student's needs or purposes, or try to solve each student's problems in academic writing in English. This macro plus micro approach is put forward and practiced under the following considerations.

\section{Needs analyses from the perspective of the present situation of English teaching in China}

In place of the more traditional "General English" courses, in the past two decades, ESP (English for Specific Purposes) teaching/learning in China has gone beyond the mere traditional EST (English for Science and Technology), extending to the more specific fields, like MBA, EMBA, MPA, and many others (Hinkel, 2005, p. 121; Hamp-Lyons, 2001). This trend of teaching and learning for ESP rather than for language itself has grown to be one of the most concerning areas of English as a Foreign Language (EFL) teaching around the world. However, at present, there has been no specific reporting on academic writing for ESP aimed at students coming from a wide range of science disciplines and with some levels of research experience.

ESP-based teaching and learning strategies and materials for teaching and learning, in the sense of EST or beyond, have been barely reported in China and, if there are any, they are more likely focused at a theoretical rather than at a practical level (Chen, 2001, pp. 28-30; Wen, 2001, pp. 23-24), or based on generalist texts (Hutchinson \& Waters, 1987; Robinson, 1991). Actually, the lack of the term English for Academic Purposes (EAP) from the English Language Teaching (ELT) sense to date does not imply that there has not been pedagogy in China specifically oriented to English for academic purposes. Nevertheless, what is lacking is the instruction on academic writing for students within various specialist disciplines for the sole purpose of meeting the referees' expectations, as well as effective teaching materials.

A noticeable phenomenon worth mentioning is, while many English teachers expect to target their language teaching at helping students solving their writing problems in English, the approaches of dealing with the problems are not always appropriate due to the fact that these teachers did not realize the model role of more high-level papers written by native speakers and did not find the right way to analyze the language genre that is required in the specific profession; that is to say, they did not realize the importance of analyzing students' needs and their problems in writing. As a consequence, we teachers sometimes could not really know what the bottlenecks are that hold back the development of Chinese scientific publication in English. It seems important to point out, as it has been previously commented by Blue (1988) that there is an important difference between English for GAP and English for SAP (Dudley-Evans, 1998).

In addition, our teaching experience and study show that there are no packaged textbooks that can completely meet the requirements of ESP teaching (for each student), no matter how satisfactory the textbooks may be in terms of GAP (General Academic Purpose) (Dudley-Evans, 1998; Hutchinson, 1987, p. 19). Therefore, there comes an immediate need for a kind of teaching approach aimed at helping students fulfilling their specific expectations through an appropriate teaching approach and materials. 


\section{Needs analyses from the perspective of target students}

The target students are non-English major doctoral candidates taking English writing class as one of the required courses for doctoral degree, two hours a week for 20 weeks during one semester. As one of the top nine universities in China, our school, Harbin Institute of Technology (HIT), has set up rules as one of the prerequisites that HIT PhD students should have their research papers published in international refereed journals before they are awarded $\mathrm{PhD}$ degrees. This requirement puts our doctoral students under a cute need and great pressure to develop the required language skills alongside their scientific expertise so that, once submitted, their papers will not be declined from publication or conference reviewers just because of linguistic problems in writing. Our investigations show that doctoral students in other key universities in China face the same tricky task as the students in our school do in this regard.

Apart from the requirements from the school, our before-class questionnaire (Questionnaire conducted at the first introductory class) and interview reveal that our doctorial students themselves have a very strong inner desire getting help from the teacher so that they can write out efficient academic papers to be presented at international meetings, or to have their research papers published in international referred journals during the course of their doctoral study at school. But the very fact is our investigations and questionnaires show that, up to now, there are comparatively few doctoral students who have actually had the experiences of writing academic texts, or ever have received the kind of training for academic writing.

Subsequently, what has been noticed is that it is quite a common phenomenon that some of our students' papers submitted to journals are rejected by the editors due to some linguistic problems, although, more often than not, the contents or ideas that are expected to express in their papers might be considered original and significant. This situation suggests that we, as English teachers of PhD students for Academic Purpose, face a potentially important task of providing instructions on developing skills of manipulating language as a vehicle to transmit academic information adequately through writing in English (Gillett \& Wray, 2006; Godfrey, 2011). However, studies demonstrate that, up to now, there is not much reporting on ESP teaching and learning in China for our students to reference, nor have we found any class situations that are the same as the ones we have now, where students attending the same class come from various disciplines but with the same purpose of having their papers indexed in various influential international citation indices.

Given this situation, this paper puts forward a new method, also called Macro plus micro approach, to English academic writing. This is a learner-centered learning and teaching approach for the core goals of developing the competence for the real-world writing tasks that $\mathrm{PhD}$ students are faced with, so as to meet the needs of doctoral candidates who learn English for communicating academic information in their specific fields, such as attending international conferences or publishing their research work in refereed journals. The specific features of this teaching approach are that this approach bases its course not only on the authoritative books or textbooks on academic writing, but also, more importantly, on the sample materials, or high-level sample research papers, that have already been published within students' own research fields and downloaded by $\mathrm{PhD}$ students themselves taken as benchmarks. Also, the methodology presented here concerns how our students are introduced to ESP instructional strategies, materials adaptation and development, and evaluation.

\section{Macro plus micro approach to English academic writing}

According to this macro plus micro approach, teaching and learning materials for the teacher and students come from two sources: one is from the teacher including reference books and hand-out materials prepared by the teacher as part of teacher's lecturing materials in class and these materials are also used by students as their previewing materials to be discussed in class. The other source is from students which are in reality high-level research papers relative to students' research fields selected and downloaded by students to be used as sample articles. These published articles in the refereed journals that are published within the latest three years serve as control materials in contrast with the materials provided by the teacher as the first source. 
The materials provided by the teacher aim at the following outcome goals:

$>$ To assist students to develop needs assessments and genre analyses adaptable for their specific majors.

$>$ To assist students to become knowledgeable about assessment procedures appropriate for major-oriented English academic writing, so as to apply this knowledge in developing their own texts that could possibly be accepted by referred journals.

$>$ To provide guidelines for students to adapt or create authentic texts in a chosen research area and to prepare for a critical evaluation of currently available sample research papers, including experimentally -based papers.

$>$ To assist students locating their problems in writing and preparing an assessment and improving plan based upon their needs assessments and discourse analyses.

> To research current foreign language teaching methodologies appropriate for the needs of students' outcome goals.

Apart from teacher's materials, research papers downloaded by students are used in contrast with the knowledge lectured by the teacher in terms of contents and rhetorical characteristics of academic papers, with special attention paid to:

$>\quad$ The common purposes shared by most academic papers;

$>$ The common rhetorical characteristics shared by most academic papers;

The style of a journal to which $\mathrm{PhD}$ students will contribute their articles in the near future;

D The commonness and differences between what is lectured by the teacher and what students learnt from consulting articles published in their fields;

$>\quad$ The specific features of academic papers in students' fields, respectively;

$>$ The aspects in which sample research papers support or contradict what is lectured by the teacher based on the teacher's reference books and hand-out materials; and

$>$ Suggestions that modifications or extensions need to be made to the teacher's materials.

Of course, students are encouraged to raise their opinions that may go beyond or above the guidelines so long as what they address seems relevant to their writing.

\section{Developing students' critical and analytical skills}

The integration of the two sources of reference materials in the course of academic writing has many merits. One of the merits is the training of our students' critical thinking through critical use of the two sources of materials provided by teachers and the ones chosen downloaded by students themselves. Students' materials provide genuine control materials as criteria to reveal part of our students' problems in writing. For example, by calculating the average number of words in our students' abstracts and the word number of the abstracts written by native speaker of English, our students find the huge difference between abstract written by native speakers and by our students; that is, the average number of words of a sentence in foreigners' abstracts is more than twice as large as the number of sentences in our students' abstracts (about 25 words per sentence vs. about 10 words per sentence). But the further analyses of the amount of information conveyed in two types of abstract, it is found amazingly that foreigners' abstracts are more informative and concise within compact form by means of, especially, the use of post-modification, such as the appropriate use of gerund, infinite, or adjective phrases which help avoid using so many meaningless functional words necessary for constructing loose clauses. 
Macro plus micro approach to English academic writing

This cultural difference has never been identified by our students before, not to say the significance of long sentences for expressing complex thoughts. Besides, as far as long sentences are concerned, our students will automatically think that they should learn to make use of clauses embedded within one another. Through evaluating the contrast abstracts according to the principle of accuracy, clarity and brevity in academic writing, and by analyzing the technical strategies the native speakers adopt in producing such compact writings, as mentioned above by using appropriate phrases rather than clauses, our students obtain the first-hand experiences of the academic features in scientific writing.

In terms of contents of abstracts, we direct our students to focus their attention on the contrast analysis of the kind of information expressed in abstracts with regard to their research work. This content-oriented analysis serves as media that enables our students to develop their critical thinking, a required disposition of academic writers. To get to know the specific kind of abstracts and the broad features that abstracts characterize in general, our students are asked to analyze the components of foreigners' abstracts downloaded and the way these components are described before they come to class for further discussion. Then, in class, we encourage our students to report their findings in the analyses. Through this activity, students realize that, although what is specifically contained in each abstract may differ a little bit from one abstract to another, the general elements that constitute abstracts are almost the same; that is, they are composed of such elements as the objective of the paper, the methodology used to conduct the research, the results of the research work or the main findings, and the conclusion or implication of the research. This generalization can be drawn based on the reporting by each student of his paper downloaded which can show clearly the general structure of an abstract. By further analyzing how each element is linguistically expressed, students learn the technique of academic writing, such as descriptive and informative writing, as well as the value of descriptive or informative writing. Under the guidance of teachers' lecturing, reference books, and hand-out materials, students are likely to pay special attention to the genres of the sample research papers that are appropriate for each student's major and that can provide them with a format in which they may put the content they have.

In this critical analyses, students need to analyze audiences, contexts, and/or communities from which the discourse arises, as well as the apparent purposes for the genre and specific ways in which the writer attempts to achieve his/her purposes with the audience, including the overall structure of the genre. And special attention is also paid to the headings and meta-genre features that are employed to hold the entire text together. The repeated, or essential, grammatical features and their relationship to genre functions are discussed, and the lexical features and their relationships to each other and the complete text are dealt with, including the visual or non-linguistic features.

During the whole process of critical analysis, students can master the most appropriate and accurate language structures through careful comparison, contrast and evaluation about the knowledge in reference books and sample articles. This comparative approach of teaching and learning practice can motivate students to adopt a critical approach to language use, both their own writing and others. For example, when students compare, contrast, and analyse different genres, registers, translations, and many others, they are also enticed to increasingly assess themselves for the contents of what they are writing, along a number of different dimensions such as (a) level of abstractness, (b) argumentation, and (c) originality of ideas. As a consequence, students become more reflective, and more critical of themselves, both linguistically and in relation to their approach to the content of their own work. They also become more independent, tending to take charge of their own learning in terms of language as well as in their research that they need to carry out in order to produce linguistic text.

\section{Assessment of teaching and learning}

\subsection{Assessment of teacher's work}


Macro plus micro approach to English academic writing has been practiced in HIT for ten semesters with more than six hundred $\mathrm{PhD}$ students taking part in this sort of writing course. Before the end of each semester, the teacher's working is evaluated through after-class questionnaire designed by the teacher herself as the feedback for the partial assessment of the ongoing course. Evaluation questions responded by students contain partially the following:

$>$ The teacher's effect on stimulating students' interest in the subject;

$>$ The teacher's effectiveness in teaching the course;

D The teacher's effectiveness in helping students develop their critical and analytical skills;

$>$ The teacher's effectiveness in helping students master the strategies in writing;

The teacher's successfulness in helping students improve their ability to work independently; and

The teacher's helpfulness in facilitating students' contact with their peers.

Also, students are encouraged to write down their suggestions on this course, so long as the course has been and will be regularly taught in this university semester after semester. Based on the feedback from the questionnaire, the course is adjusted wherever is not so effective, or not so successful or not so helpful. The contents of the course will also be supplemented or partially eliminated according to students' ideas and responses on what is needed and what is unpractical for this course. So from this respect, we can say that the course design is flexible in the sense that it is modified and perfected constantly while it is practiced in class (See Appendix 1).

\subsection{Assessment of students' learning}

To evaluate students' study, considerations are devoted to both their writings and participation in class activities. Their writings include such assignments as abstract writing, essay writing, and research paper writing; and grading is also based on students' participation in class and their interactions with the teacher and peers, which reflect their knowledge of ESP issues under discussion and a critical integration of what has been learned from lectures, readings, and the student's own experience. More specifically, students are required to keep up with the readings, the class arrangement, and the ongoing course, so as to be mentally active and prepared when they are called on for relevant materials and/or for their response during class. Their grades will be affected by their participation in class--asking and answering questions, raising relevant issues, which accounts for $10 \%$ of the total grade.

Students are graded on their oral contribution in class, including quality of insight, ability to connect ideas, as well as manner of oral presentation (clarity, use of reasons, audibility, critical but cooperative interaction with others, etc), amounting to $10 \%$ of the total grade. Assigned homework writings tend to help students grapple with the ideas delivered and discussed in class and also to help the teacher measure how much students understand the course. Assignments are corrected by both the teacher and the students themselves. Writing assignments take $20 \%$ of the total grade. Final exam (summary writing and essay writing) accounts for $60 \%$ of the total grade.

The process of correcting student's assignments involves both the teacher and students. That is, each student E-mails their homework to both the teacher and other students for reviewing and correction. Then, in the following class, all the students and the teacher present their ideas and comments on these assignments one by one based on reference criteria provided by the teacher and students' previous knowledge of language (See Appendix 2). This practice is helpful and welcomed, since all the issues discussed pertain to students' concerns in writing, which is confirmed by the feedbacks from students in and after class responses. 


\section{Conclusion}

Unlike those who learn language with a view to learning the linguistic features and literary values, $\mathrm{PhD}$ students learn language primarily and basically as a vehicle for the sake of communicating within academic circles and exploiting and expressing something altogether different from linguistic features of language. Thus, when talking of major oriented academic writing, one important issue to which particular attention should be paid is that the teaching method of academic writing in English should have its base in needs-analyses. English language, when learnt for a specific purpose, should be taken more as a medium of receiving and reproducing the knowledge of the other domains of curriculum under study, than as a separate subject to study. The crucial role of teaching English language is to meet the needs of academic communications within students' majors.

This proposed approach to English academic writing can greatly enhance $\mathrm{PhD}$ candidates' confidence and competence in their academic writing by effectively tailoring the teaching of English (courses) to students' needs and their own strategies of solving their individual problems. Teachers and students should rely more on authentic source materials from students' majors as part of benchmarks in teaching and learning practice than on the published textbooks available. Through critical interaction between teachers and students, the suitability of academic textbooks will be evaluated in contrast with the authentic source materials, as well as verified, modified, or extended to the extent that they can become more adaptable for students' purposes to have their papers accepted and published in their refereed journals. More importantly, this macro plus micro approach to English academic writing can help learners find their confidence in learning and utilizing English language in their academic community, as well as help them deep-learn cultures of self and others, thus resulting the learners in becoming more competent participants in academic communication in a progressive manner.

\section{References:}

Blue, G. (1988). Individualizing academic writing tuition. In P. Robinson. (Ed.) Academic writing: Process and product. ELT Documents, 129.

Cargill, M., \& O’Connor, P. (2009). Writing scientific research articles: Strategy and steps. Wiley-Blackwell.

Chen, L. N. (2001). The theoretical basis of ESP. Foreign Languages and Their Teaching, 12(2), 28-30.

Dudley-Evans, T., \& St. John, M. J. (1998). Developments in English for specific purposes. Cambridge.

Gillett, A. J., \& Wray, L. (2006). Assessing the effectiveness of EAP programmes. London: BALEAP.

Godfrey, J. (2011). Writing for university. London: Palgrave.

Hamp-Lyons, L. (2001). English for academic purposes. In R. Carter \& D. Nunan (Eds.), The Cambridge guide to teaching English to speakers of other languages (pp. 126-130). Cambridge: Cambridge University Press. <http://dx.doi.org/10.1017/CBO9780511667206.019>

Hinkel, E. (Ed.) (2005). Handbook of research in second language teaching and learning. Singapore: Nanyang Technological University.

Hutchinson, T., \& Waters, A. (1987). Writing for academic purpose. ESP World, 2(28). Retrieved July 15, 2012, from http://www.esp.-world.info

Li, X. W. (2011). English academic writing. Beijing: China Machine Press.

Robinson, P. (1991). ESP today: A practitioner's guide. NY: Prentice Hall International.

Wen, J. (2001). On the teaching and researching fields of ESP. Foreign Languages and Their Teaching, 12, $23-24$. 


\section{Appendix 1}

\section{Student Questionnaire to Evaluate the Teacher's work}

\begin{tabular}{|l|c|}
\hline $\begin{array}{l}\text { How would you rate the teacher's ability to integrate this teaching with your } \\
\text { participation in the subject? }\end{array}$ & Excellent 12345 Poor \\
\hline How effective have you found the teacher in teaching this course? & Very effective 12345 Not at all \\
\hline $\begin{array}{l}\text { How well did the teacher combine his lecturing and your involvement in the } \\
\text { practical setting? }\end{array}$ & Very effective 12345 Not at all \\
\hline $\begin{array}{l}\text { Did the teacher link practical work and information provided in students' } \\
\text { samples materials and lectures? }\end{array}$ & Regularly 12345 Rarely \\
\hline $\begin{array}{l}\text { Did the teacher encourage you to think through critical problems for yourself? } \\
\text { student participation? }\end{array}$ & Very often 12345 Seldom \\
\hline $\begin{array}{l}\text { Did the teacher value the knowledge and experience you brought to class? } \\
\text { How helpful was the teacher in assisting you to become familiar with writing } \\
\text { features in your research field? }\end{array}$ & Very well 12345 Poorly \\
\hline $\begin{array}{l}\text { How effective was the teacher in helping you to develop your critical and } \\
\text { analytical skills in academic writing in English? }\end{array}$ & Regularly 12345 Rarely \\
\hline $\begin{array}{l}\text { Was the teacher effective in helping you to integrate theory and practice? } \\
\text { Did the teacher help you to improve your communication skills? }\end{array}$ & Very effective 12345 Not at all \\
\hline $\begin{array}{l}\text { Did the teacher help you to develop confidence in using what you learned in the } \\
\text { course? }\end{array}$ & Very effective 12345 Not at all \\
\hline $\begin{array}{l}\text { Was the way of treating assignments constructive? } \\
\text { your ability to write academic texts in English? }\end{array}$ & Definitely 12345 Not at all \\
\hline $\begin{array}{l}\text { Was the teacher receptive to differing viewpoints or opinions? } \\
\text { Is aph so } 12345 \text { Not at all }\end{array}$ \\
\hline
\end{tabular}

Specify your viewpoints on what should be eliminated from or supplemented into the course, or any ideas for the teacher to improve her work.

\section{Appendix 2}

\section{Criteria for evaluating Academic Text}

\begin{tabular}{|l|l|}
\hline Manuscript: & Follow the guidelines in the journal and style manual, submit a clean manuscript. \\
\hline Thesis: & State thesis clearly, appropriately and maturely. \\
\hline Organization: & $\begin{array}{l}\text { Arrange material according to an appropriate logic and appropriate plan; think about } \\
\text { the audience and its interests; show significance to the reader and the field; } \\
\text { emphasize what is relevant; omit unnecessary reference to your own; state the } \\
\text { problem, significance, results; don't try to cram too much detail into the text. }\end{array}$ \\
\hline Paragraphs: & $\begin{array}{l}\text { Be coherent with smooth transitions } \\
\text { Repetition of key words and phrases } \\
\text { Pronoun reference } \\
\text { Parallelism }\end{array}$ \\
\hline Language: & $\begin{array}{l}\text { Write clearly, distinctly, and concisely; avoid esoteric jargon and common stylistic } \\
\text { errors, such as non-parallel headings, weak transition into section, ambiguity from } \\
\text { missing punctuation, ambiguity from pronoun, ambiguity from word order, lack of } \\
\text { sentence variety, needlessly complex words, needlessly complex noun phrase, } \\
\text { needlessly complex sentence, run-on sentence, verb tense error, subject-verb } \\
\text { disagreement, and usage error, etc. }\end{array}$ \\
\hline Be mature and substantial with relative points and illustrative material. \\
\hline Content: & $\begin{array}{l}\text { Be original; that is, arguments should be new and different. Ideally, the results or } \\
\text { conclusions being reported on should be somewhat unexpected. }\end{array}$ \\
\hline Arguments:
\end{tabular}

